\title{
GROWTH OF THE BODY AND OF THE VARIOUS ORGANS OF YOUNG ALBINO RATS AFTER INANITION FOR VARIOUS PERIODS.
}

\author{
CHESTER A. STEWART,
}

Institute of Anatomy, University of Minnesota, Minneapolis. (Five Tables and Four Charts.)

\section{Contents.}

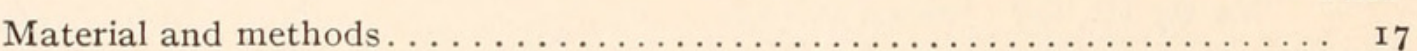

Alternate fasting and refeeding experiments ............... 2 I

Refeeding after various periods of maintenance................ 23

I. Growth in body weight . . . . . . . . . . . . . . . 23

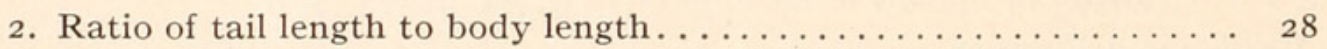

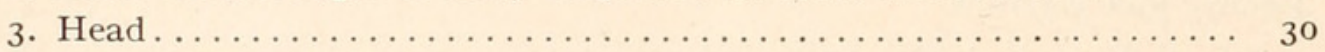

4. Extremities and trunk .................... 3 I

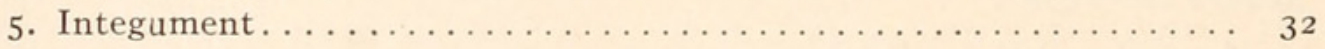

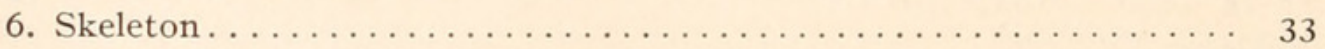

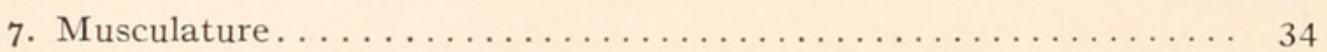

8. Viscera and "remainder" . . . . . . . . . . . . . . . 35

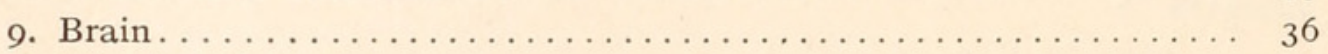

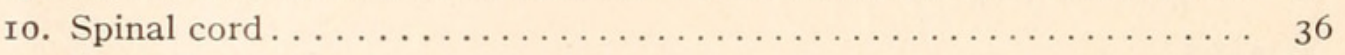

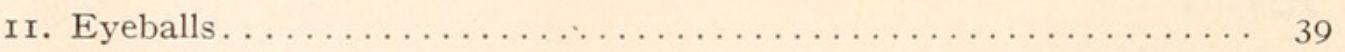

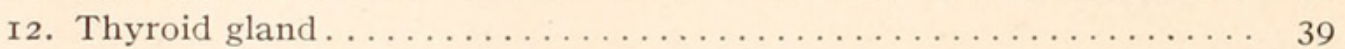

13. Thymus............................

I4. Heart. . . . . . .

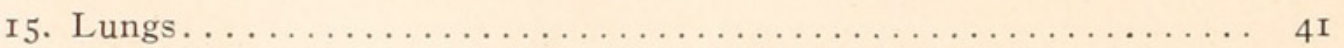

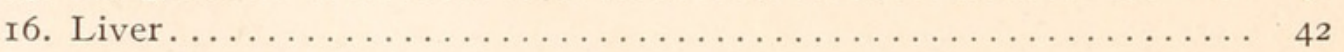

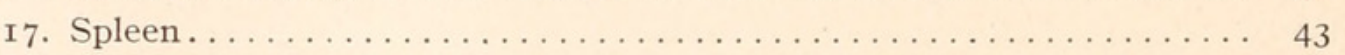

I8. Stomach and intestines......................... 43

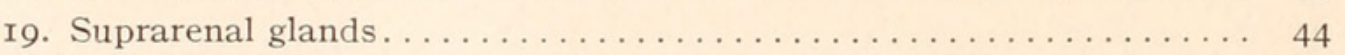

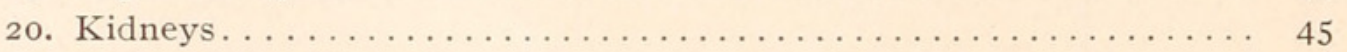

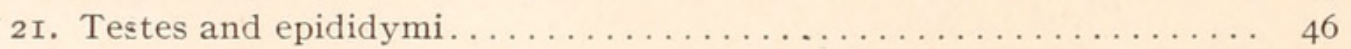

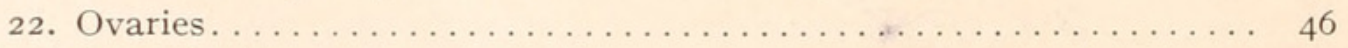

23. Hypophysis . . . . . . . . . . 47

24. Pineal body . . . . . . . . . . . . . . . . . . . 47

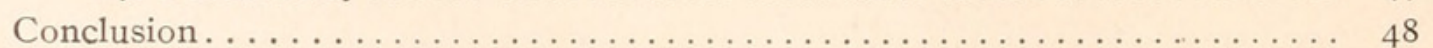

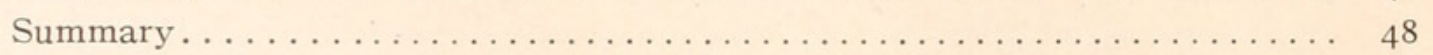

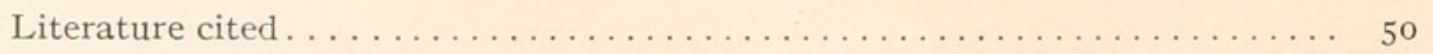

Recent investigators have found that the capacity for growth is not lost in young albino rats held at nearly constant body weight for considerable periods, although important changes have taken 
place in the various organs. When animals thus stunted are generously fed, one of three results might be expected concerning their recovery: (I) There might be a complete recovery in the weight of the body as a whole, with normal proportions of the individual organs and parts. (2) Since the growth impulse and the power of maintenance varies considerably in the different organs and parts of the body, one might expect certain individual organs to show lingering effects of stunting. (3) If the stunting were sufficiently severe to lower the final adult body weight, then the different organs and parts might be either similarly or dissimilarly affected. Thus in the first case, an adult of normal size and proportions would be obtained; in the second case, an adult of normal size but abnormal proportions; in the third case, a dwarf of either normal or abnormal proportions.

Numerous observations are recorded in the literature on the recovery of the body weight as a whole in different animals upon refeeding after various periods of growth suppression; but very few observations have been made upon the individual organs and parts. A more complete and thorough study of this question seemed desirable, and therefore the present investigation was undertaken. This opportunity is taken to express my indebtedness to Dr. C. M. Jackson for valuable aid and direction.

\section{Material and Methods.}

For the present experiments eight litters of albino rats (Mus norvegicus albinus) were used (Table I.), which included twenty males and twenty-five females, a total of forty-five.

The experiments began when the rats were three weeks of age (time of weaning). From most of the litters, at the beginning of the experiment, one rat of each sex was selected to serve as an (initial) control, the sex being identified by the method of Jackson ('I2). Of the nine controls thus selected, two were killed at sixteen weeks of age, and four at about one year; while three were well fed until thirty-nine weeks of age, at which time the experiment for which they were the controls (alternate fasting and refeeding) was discontinued.

In addition to the direct controls, the observations by Jackson and Lowrey ('I2), Jackson ('15) and the Wistar norm tables of 
Donaldson ('15) were of great value for comparison. In referring to Donaldson's norm throughout the paper, comparison is always made with the weight in animals of corresponding body length, according to the method recommended by Donaldson ('I5).

Of the rats subjected to inanition, eighteen were held at nearly constant body weight from three to twelve weeks of age, and killed after being refed one half week ( 2 rats), one week (5 rats), two weeks ( 5 rats), or four weeks ( 6 rats). In addition, two rats of this series were killed at the end of the maintenance period from three to twelve weeks of age. Thirteen rats were refed until adult (about I year old) after being held at constant body weight for various periods: from the age of three weeks to age of four weeks (4 rats), from three to six weeks (4 rats), and from three to ten weeks (5 rats). The test rats of litters S23 and S24 were held repeatedly at constant body weight for short periods during the first two or three months, and during the intervening times were amply fed. Later a different plan was adopted, the rats of these two litters being alternately severely starved and refed.

The rats were kept in ordinary wire cages provied with wire net bottoms, which permitted feces and other waste materials to drop into the box base below. It is necessary to use this type of cage to prevent the underfed rats from eating their feces. The cages were kept as clean as possible, and the rats remained healthy with the exception of some lung infection, especially among the older rats.

The temperature of the room in which the control rats were kept remained usually at about $2 \mathrm{I}^{\circ} \mathrm{C}$. $\left(70^{\circ} \mathrm{F}\right.$.), but occasionally it dropped as low as $16^{\circ} \mathrm{C}$. $\left(56^{\circ} \mathrm{F}\right.$.). Inasmuch as underfed rats are very susceptible to cold (even a slight chilling being sometimes fatal), a part of them, litters Stio, StI I, StI2, were kept in a separate room where the temperature ranged constantly between $27^{\circ}$ and $32^{\circ} \mathrm{C}$. $\left(80^{\circ}\right.$ and $90^{\circ} \mathrm{F}$.). The reduced power of the underfed rats to resist cold is probably due to the exhaustion of reserve material in the body, which ordinarily would be oxidized to maintain the normal temperature.

In spite of keeping the test rats very warm, it was found very difficult to hold them strictly at constant body weight for more 
than thirteen or fourteen weeks, and keep them alive; so as a rule they were permitted to increase slightly in body weight after that time. Aron ('II) and Jackson ('I5) similarly found it increasingly difficult to hold animals at constant body weight as the experiment progressed.

Individual weight records were kept, the individuals rats being identified by staining the integument with an aqueous solution of picric acid. The weight of the rats was always recorded immediately before feeding. The test rats were weighed daily; whereas the controls were weighed at gradually increasing intervals (about once a week after reaching 200 grams body weight).

Previous to reaching sexual maturity the control males and females were usually separated in order to prevent pregnancy. In the case of the stunted rats it was found unnecessary to separate the sexes while being underfed, for in no case did a pregnancy result, although of litter No. S8 the control female and also those rats refed after one and three weeks of maintenance each bore one litter.

All the rats were fed on whole wheat (Graham) bread soaked in whole milk. The control rats were given an abundant amount of food, whereas the test rats received during the underfeeding just that amount of food required to hold them at nearly constant body weight. It was observed that the test rats did not eat their entire maintenance ration immediately until after about two weeks of underfeeding. Aron ('I I ) noted that at first it was necessary to feed a dog its maintenance ration in two portions, but after a short time it was able to eat its entire allowance at a single feeding. Water in abundance was given to all the animals.

It was found, as was observed by Jackson ('I5), that the rats are for a time held at constant body weight upon a gradually diminishing ration. It was further observed, however, that after about fifty days of maintenance there is no further decrease in the necessary amount of food. In one litter, the average amount was found to remain practically constant from the 6oth to the I2oth day of the experiment.

After being held at maintenance, the test rats were generously fed for different periods as indicated in Table I. At the end of 
the experiment they were killed and autopsied according to the method used by Jackson ('15), with a few modifications.

\section{TABLE I.}

RECORD OF LITTERS USED.

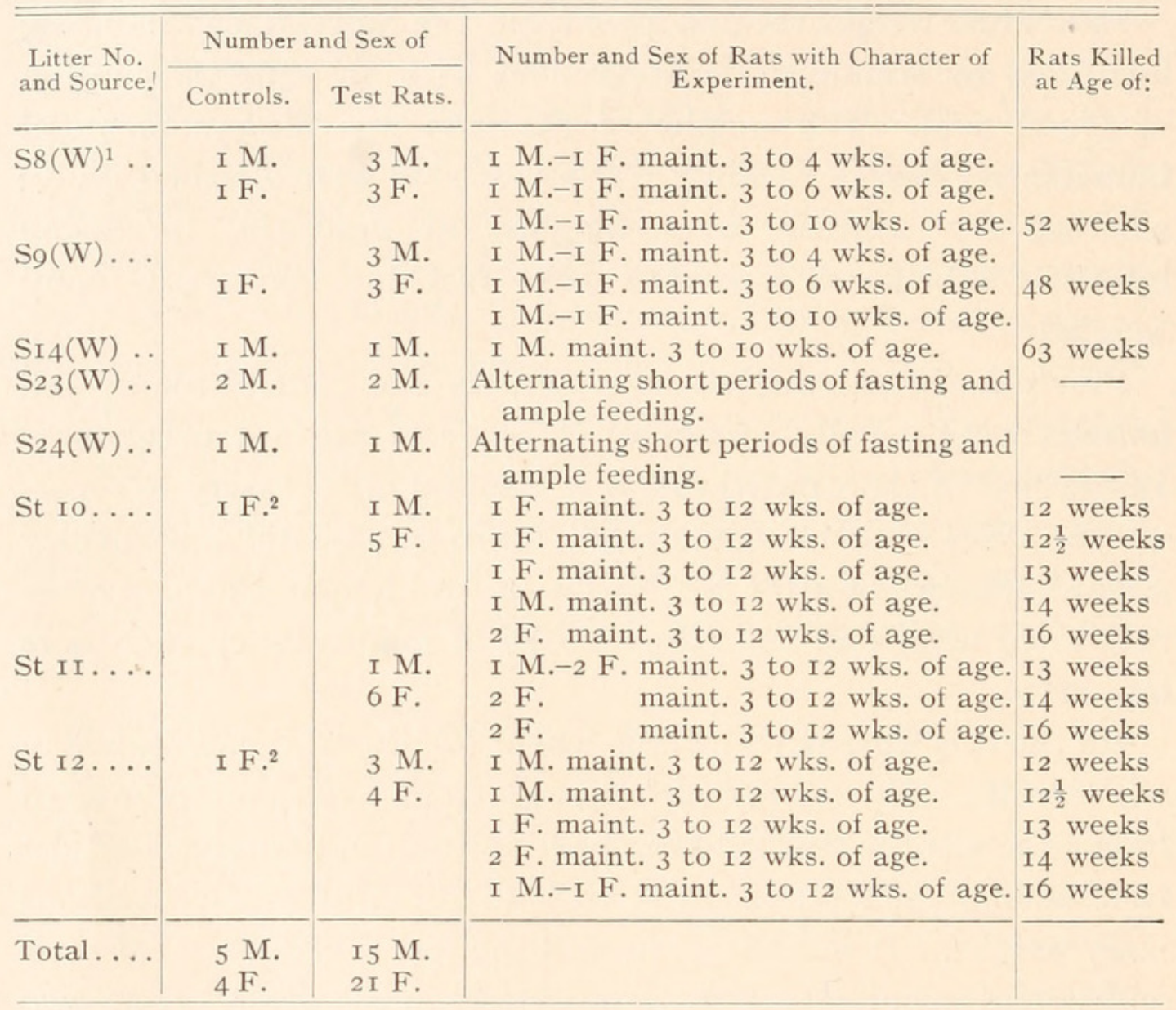

For economy of space, only the average data are indicated in most cases in this paper. A copy of the cards containing the individual data will be filed in the Wistar Institute of Anatomy (Philadelphia) however, where they will be accessible to anyone interested.

On account of the relatively small number of observations, and the known variability of the various organs, the data are inconclusive in some cases. They are, however, sufficient to show clearly some of the more obvious and important changes in the rats refed after various periods of maintenance.

An abstract of the present paper has been published in the

${ }^{1} W=$ litters from Wistar stock; the others are from Minnesota stock.

${ }^{2}$ Controls in litters St Io and St I 2 killed at I6 weeks of age. 
Proceedings of the American Association of Anatomists, New Haven meeting, Dec., I9I5 (Stewart, 'I6).

\section{Alternate Fasting and Refeeding Experiments.}

The two litters utilized for the alternate fasting and refeeding experiments included six rats (Table II.), of which three served as the test animals, and three as the controls. The former were frequently held at constant body weight for short periods $(3-4$ days), and abundantly fed during the intervening time. With each repeated fast the body weight was held constant at a progressively higher level.

TABLE II.

The Gain in Body Weight in Male Rats Refed after Being Held at a

Constant Body Weight for Short Repeated Periods, as Compared With THE CONTROLS.

\begin{tabular}{|c|c|c|c|c|c|c|c|}
\hline $\begin{array}{l}\text { Litter } \\
\text { No. }\end{array}$ & Rat No. & $\begin{array}{l}\text { Total No. of } \\
\text { Days the Rats } \\
\text { Were Held at } \\
\text { Maintenance. }\end{array}$ & $\begin{array}{c}\text { No. of Days } \\
\text { the Rats } \\
\text { Increased } \\
\text { in Body } \\
\text { Weight. }\end{array}$ & $\begin{array}{l}\text { Initial Wt. } \\
\text { of Rats in } \\
\text { Grams. }\end{array}$ & $\begin{array}{l}\text { Final Wt. } \\
\text { of Rats in } \\
\text { Grams. }\end{array}$ & $\begin{array}{l}\text { Total Gain } \\
\text { in Grams. }\end{array}$ & $\begin{array}{l}\text { Daily } \\
\text { Average } \\
\text { Gain in } \\
\text { Grams. }\end{array}$ \\
\hline $\begin{array}{l}\mathrm{S}_{23} \\
\mathrm{~S}_{23} \\
\mathrm{~S}_{23} \\
\mathrm{~S}_{23} \\
\mathrm{~S}_{24} \\
\mathrm{~S}_{24}\end{array}$ & 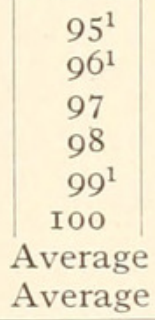 & $\begin{array}{c}0 \\
0 \\
42 \\
42 \\
0 \\
40 \\
\text { for controls } \\
\text { for test rats }\end{array}$ & $\begin{array}{r}\text { I } 43 \\
\text { I } 43 \\
\text { IOI } \\
\text { IOI } \\
\text { I } 2 \text { I } \\
7 \text { I }\end{array}$ & $\begin{array}{l}22.4 \\
24.1 \\
22.8 \\
22.1 \\
20.8 \\
19.0 \\
22.4 \\
21.3\end{array}$ & $\begin{array}{l}276.0 \\
218.0 \\
246.0 \\
247.0 \\
254.0 \\
245.0 \\
249.3 \\
246.0 \\
\end{array}$ & $\begin{array}{l}253.6 \\
193.9 \\
223.2 \\
224.9 \\
233.2 \\
226.0 \\
226.9 \\
224.7 \\
\end{array}$ & $\begin{array}{l}1.77 \\
1.36 \\
2.21 \\
2.22 \\
1.93 \\
3.18 \\
1.69 \\
2.54\end{array}$ \\
\hline
\end{tabular}

For each litter the average daily increase in body weight (Table II.), when growth was permitted was somewhat higher in the test rats than in the controls. Thus the average final weight of the controls, 249.3 grams, was nearly reached by the test rats (average 246.0 grams), although the latter had a much shorter period of actual growth.

On the whole, therefore, the data show the growth of the test rats after short periods of maintenance to be unusually rapid, so they were able to overtake the controls. Seland ('88), however, noted that rabbits and chicks enduring alternate short periods of fasting and generous feeding, became even heavier than the controls. Apparently he obtained a stimulation of growth which enabled the test animals to exceed the controls.

${ }^{1}$ Controls. 
Since this difference in degree of stimulation might possibly be due to the fact that Seland's animals suffered a more severe starvation than mine, it was decided to starve my rats more severely than had previously been done. The test rats of litter S23 were therefore subjected to starvation for three days, and the test rats of litter $\mathrm{S}_{24}$ for four days. They were then abundantly fed for 15 and 20 days respectively, but still failed to exceed the controls in body weight, and showed no tendency to do so. Noè ('oo) noted little or no over-compensation in body weight in rats refed after repeated periods of starvation.

TABLE III.

The Average Daily loss in Grams in Male Albino Rats Following Repeated Severe Starvation.

\begin{tabular}{|c|c|c|c|c|c|c|c|c|}
\hline $\begin{array}{l}\text { Litter } \\
\text { No. }\end{array}$ & Rat No. & $\begin{array}{l}\text { No. of } \\
\text { Fast. }\end{array}$ & $\begin{array}{l}\text { Days } \\
\text { Fasted. }\end{array}$ & $\begin{array}{c}\text { Wt. Before } \\
\text { Fast, G. }\end{array}$ & $\begin{array}{l}\text { Wt. at End } \\
\text { of Fast, G. }\end{array}$ & $\begin{array}{l}\text { Loss in } \\
\text { Grams. }\end{array}$ & $\begin{array}{c}\text { Loss, } \\
\text { Per Cent. }\end{array}$ & $\begin{array}{c}\text { Average } \\
\text { Daily } \\
\text { Loss, G. }\end{array}$ \\
\hline $\mathrm{S}_{24}$ & IOO & First & 7 & 269.5 & 202.6 & 67.5 & 25.0 & 9.6 \\
\hline $\mathrm{S}_{24}$ & IOo & Second & 7 & 269.0 & $20 \mathrm{I} .8$ & 67.8 & $25 . \mathrm{I}$ & 9.6 \\
\hline $\mathrm{S}_{23}$ & 97 & First & 6 & 240.0 & I 77.5 & 62.5 & 26.0 & I0. 4 \\
\hline $\mathrm{S}_{23}$ & 97 & Second & 7 & $24 \mathrm{I} \cdot 5$ & I 77.5 & 64.0 & 26.5 & 9.I \\
\hline $\mathrm{S}_{23}$ & 98 & First & 7 & 254.8 & I9I.O & 63.8 & 25.0 & 9.1 \\
\hline $\mathrm{S}_{23}$ & 98 & Second & 8 & 259.5 & I92.0 & 67.5 & 26.0 & 8.4 \\
\hline
\end{tabular}

Later the test rats of these two litters ( $\mathrm{S}_{23}$ and $\mathrm{S}_{24}$ ) were used to investigate another point. Kahan ('85) observed that in pigeons the daily average loss in weight increased with each repeated fast involving a loss of 30 to 45 per cent. of the initial body weight. My data (Table III.) show practically no tendency for the daily loss in body weight to increase in rats in repeated severe starvation periods. In fact the average loss for rats Nos. 97 and 98 was slightly less during the second fast than during the first, which suggests that possibly their power to resist starvation had been increased. The difference between my results and those obtained by Kahan may be due to the fact that his animals were more severely starved than mine. It is also probable that different species, as well as different individuals of the same species, may react differently in this respect.

Following the periods of severe starvation the amount of food eaten daily by the rats above mentioned, and their resultant weight, were carefully observed. During the first four days of 
refeeding, the body weight of the rats increased from an average of I 90.2 grams (range I 77.5-202.0), to an average of 227.8 grams (209.0-246.0). The average amount of food eaten during the four days of refeeding was 247.7 grams (195-304), which produced an actual average increase of 37.6 grams (3I.5-44.0). Thus on the average I5.I per cent. (I3.4-I6.6 per cent.) of the ingested food was applied toward increment of body weight (not taking into account the weight of ingested water and salts). In this respect my results are markedly different from those obtained by Morgulis ('I I), who found the increase in body weight of starved salamanders following refeeding might even exceed the weight of the ingested food. The absorption of water, however, is doubtless much greater in the case of the salamanders, which probably accounts for the difference.

To summarize, the fasting and refeeding experiments yielded the following results: (I) The daily average gain in weight was greater in the test rats on generous feeding following short periods of fasting than in the controls. The test rats were thus able to overtake (but not to exceed) the controls. (2) The average daily loss in weight did not increase on suffering a second period of starvation, causing a loss of 25 per cent. of the initial body weight. (3) The gain in weight following the severe fasts did not exceed I6.6 per cent. of the weight of the ingested food. (4) So far as body weight is concerned, the rats recovered completely on refeeding after having lost 25 per cent. of their initial body weight.

Refeeding after Various Periods of Maintenance.

I. Growth in Body Weight.

The average absolute increase in body weight of the test rats refed after the various periods of maintenance, and of the full-fed controls of litters S8, S9, and Si4, is represented by the growth curves in charts $A$ and $B$. The curves show that the growth of the stunted rats on generous feeding was considerably higher for some time than the normal for the (younger) controls of the same body weight, which enabled the test rats to overtake the controls before the end of the normal growth period. 
The unusually rapid growth of the test animals is more strikingly shown in charts $C$ and $D$, in which the growth curves of the rats refed after seven weeks of maintenance are superimposed upon the growth curves of the normal rats, so that their starting

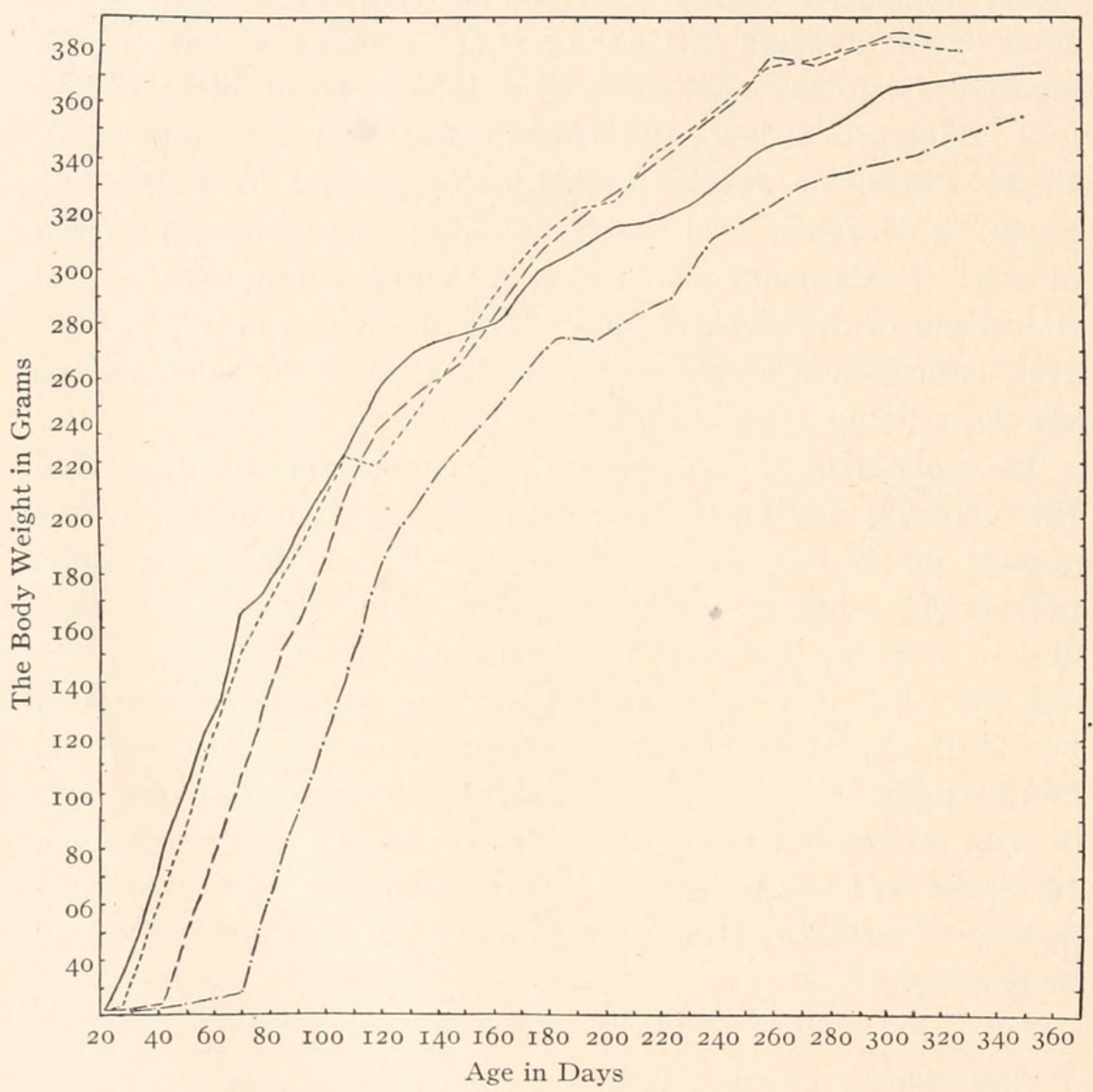

Chart A. Males. Chart showing the average absolute increase in weight of the control male rats from the age of three weeks, and also of the test males refed after various periods of maintenance. The curves are drawn through points representing the averages of the individual weights of the rats of litters S8, S9, and $\mathrm{S}_{4}$, at the various periods. Body weight in grams is represented on the ordinate and age in days on the abscissa. Controls. -. Rats refed after one week of maintenance. - - - Rats refed after three weeks of maintenance. $-\cdot-\cdot-$ Rats refed after seven weeks of maintenance.

points coincide. The curves thus constructed show an initial rapid divergence due to the more rapid growth of the test rats during the first few weeks of refeeding. Thus the stunted rats 
reach the same ultimate body weight as the controls, but in a much shorter period of actual growth. The results therefore agree with those previously stated for the rats subjected to repeated short periods of alternate fasting and refeeding.

This phenomenon of rapid growth following periods of suppression has been observed in various animals by Schapiro ('05) (cat), Hatai ('o7) (rat), Miss Springer ('o9) (salamander),

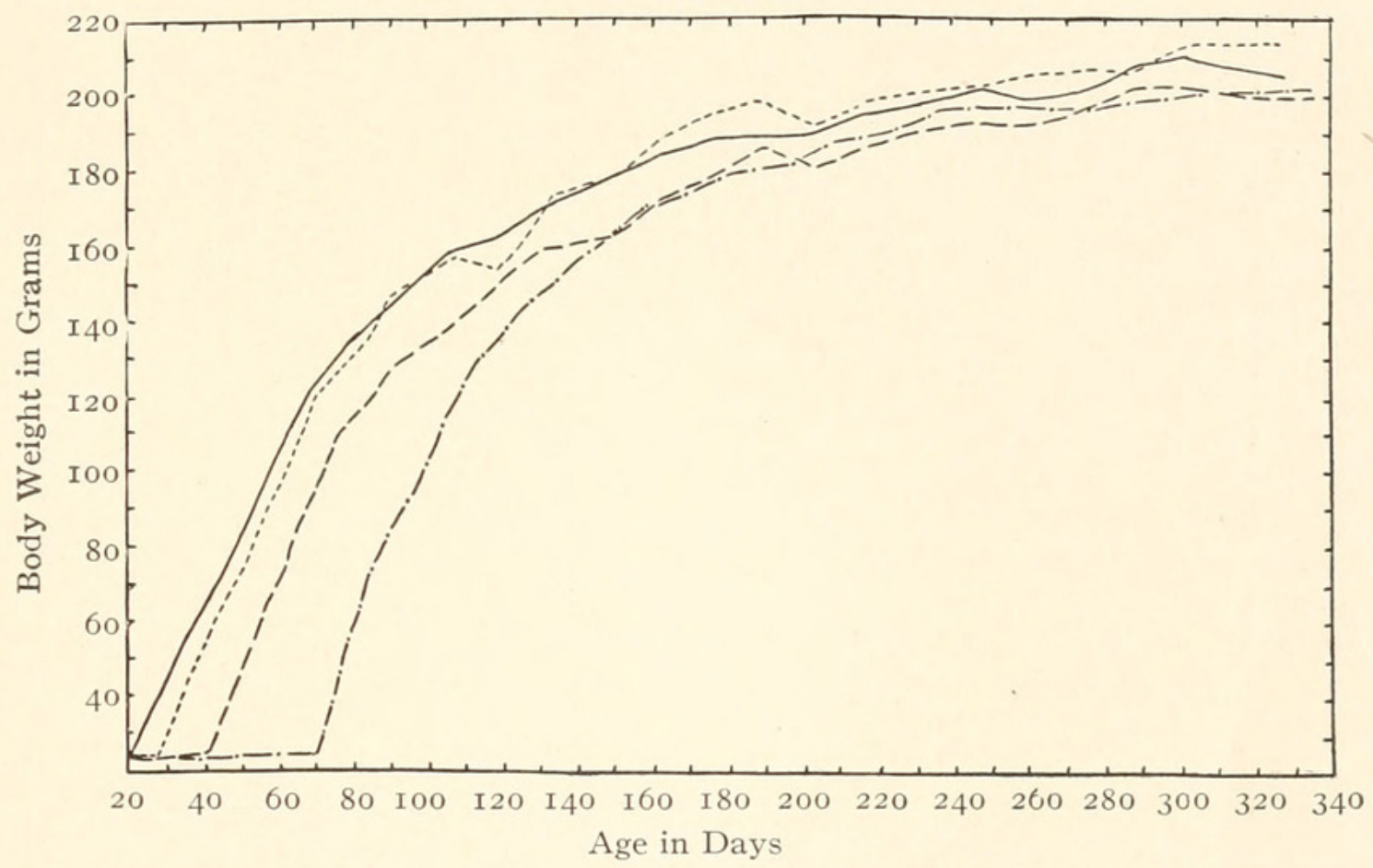

Chart B. Females. Chart showing the average absolute increase in weight of the control female rats from the age of three weeks, and also of the test females refed after various periods of maintenance. The curves are drawn through points representing the averages of the individual weights of the rats of litters S8, S9, and $\mathrm{S}$ 4, at the various periods. Body weight in grams is represented on the ordinate and age in days on the abscissa. — Controls. - - Rats refed after one week of maintenance. - - - Rats refed after three weeks of maintenance. $-\cdot-\cdot-\cdot$ Rats refed after seven weeks of maintenance.

Morgulis ('II) (salamander), Schloss ('II) and Boas ('I2) (human), Miss Ferry ('I3) (rat), Osborne and Mendel ('I5 and 'I6) (rat), and others. Osborne and Mendel find that after periods of suppression by various methods the growth upon refeeding appears even more rapid than King's ('I5) normal for younger rats of the same size. Although no direct controls were observed their results are very striking.

If we accept Minot's ('o8) theory that the relative abundance 
of nuclear material in embryonic cells accounts in part for the greater intensity of embryonic growth, we may in part account for the rapid growth following inanition upon the same principle, the changed nucleus-plasma relation. For it is well known that

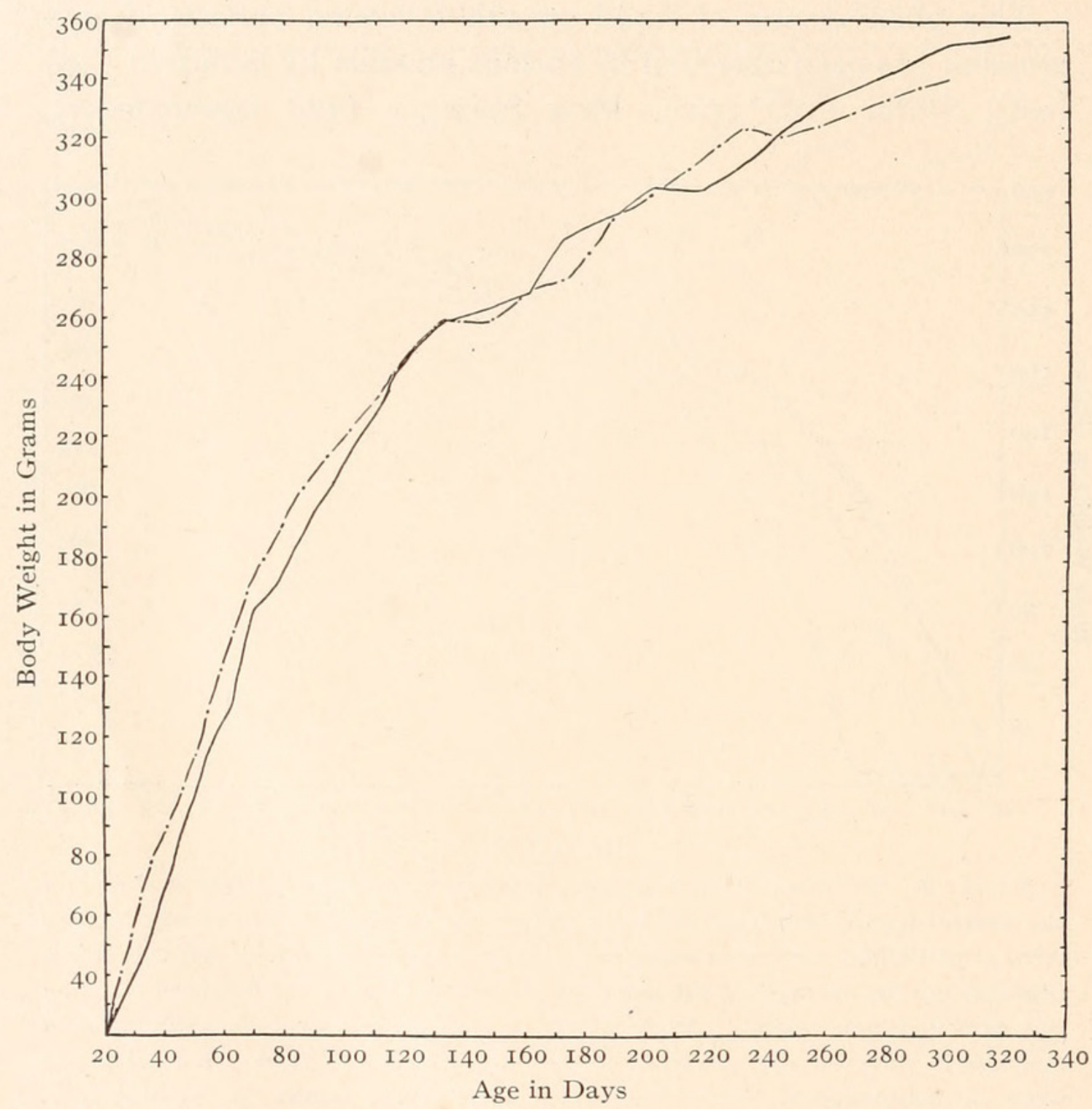

Chart $C$. Males. Chart showing the curve of growth of the test male rats refed after maintenance from three to ten weeks of age, superimposed upon that of the control males, so that the starting points coincide. The curves are drawn through points representing the averages of the individual weights of the rats of litters S8, S9 and Si 4, at the various periods. Body weight in grams is represented on the ordinate and age in days on the abscissa.

Controls. - - - - - . Rats refed after seven weeks of maintenance.

during inanition the cell nucleus becomes relatively large, the loss of substance being greater in the cytoplasm. Thus inanition tends to reduce the body cells to an embryonic condition, as found by Child ('I5) in extensive experiments upon Planarians. It is also possible that the accelerated growth following periods 
of suppression is due to specific histological changes in the ductless glands, as suggested by Osborne and Mendel ('I6).

In part, however, especially in the first few days of refeeding, the apparent increase in body weight is due to increase in contents of the alimentary canal (and possibly also in the circulating media of the body), which represent increase in gross body weight, but not actual growth of the tissue-cells.

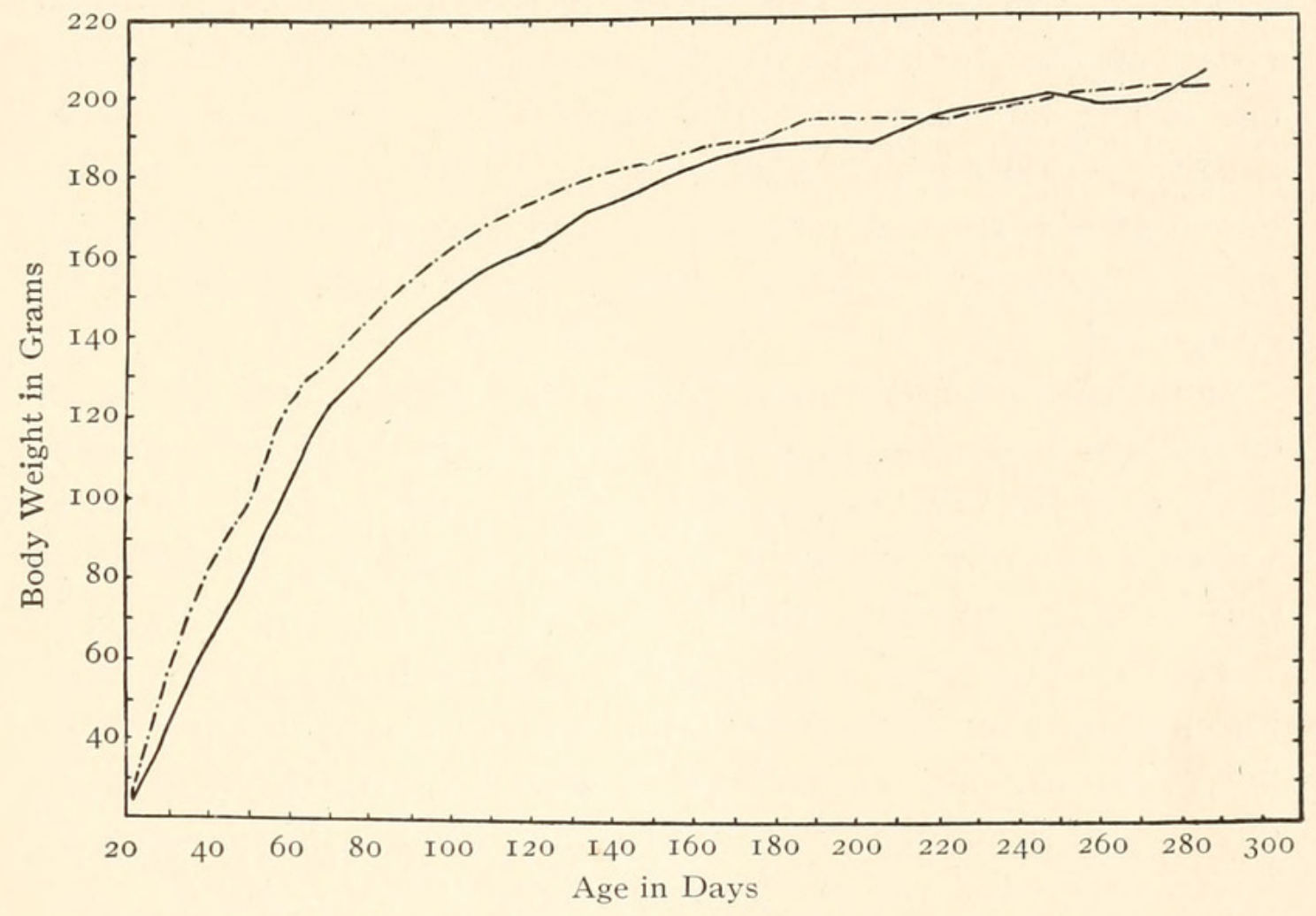

Chart D. Females. Chart showing the curve of growth of the test females refed after maintenance from three to ten weeks of age, superimposed upon that of the control females, so that the starting points coincide. The curves are drawn through points representing the averages of the individual weights of the rats of litters S8, S9, and Si 4 , at the various periods. Body weight in grams is represented on the ordinate and age in days on the abscissa. Controls. $-\cdot-\cdot-$ Rats refed after seven weeks of maintenance,

The rapid growth of the test rats which enabled them to overtake the controls, however, did not persist beyond the point when the normal adult weight was reached. This is evident from the fact that the average adult body weight of the refed animals (Table III.) was not greatly different from that of the controls. Although the controls averaged slightly higher than the test rats of the same sex, the differences are too small to be considered significant. The final weight of the males refed after seven weeks of maintenance averaged considerably below that 
of the controls, but this was probably due to chance variation, and does not indicate an actual stunting of the test rats. The females show complete recovery.

Aron ('I4) noted no permanent stunting effects on the body weight in young rats underfed less than I5o days. Osborne and Mendel ('I5, 'I6) have likewise observed attainment of normal adult body weight after suppression of growth during a period equal to or exceeding the normal growth period. One female (2033) stunted by feeding on a limited quantity of food after the age of $5 \mathrm{I} 3$ days increased from 59 grams to 222 grams in body weight. Osborne and Mendel ('I6) in their rats refed after extended periods of growth suppression note a marked tendency even to exceed the normal ultimate body weight observed by King ('I5).

In my experiments, the inanition period was begun in rats at an earlier age ( 3 weeks) than in the investigations just mentioned. Even in these very young rats, however, the recovery in body weight is usually complete, upon refeeding after maintenance periods of one to seven weeks.

The experiments of Brüning ('I4), however, indicate that stunting produced by subjecting newborn rats to repeated periods of fasting during the normal nursing period may persist, at least until fifty-four days of age, the test animals usually showing no tendency toward compensatory overgrowth when placed upon an artificial mixed diet. Whether or not complete recovery might occur later was not determined.

\section{Ratio of Tail Length to Body Length (Table IV.).}

Jackson ('I5) noted that in young albino rats held at constant body weight, the ratio of the tail length to the body length increases from an average of .66 (normal) at three weeks to .84 at ten weeks. In the two rats killed at the end of nine weeks of maintenance the tail-ratio (Table IV.) was .93 and .89, which shows that in my rats the tail likewise became relatively long during the inanition period.

At the end of each period of refeeding (Table IV.), the average tail-ratio, in the test rats (with two exceptions) ranged between .80 and .84 , which is a little below the normal for rats of corre- 


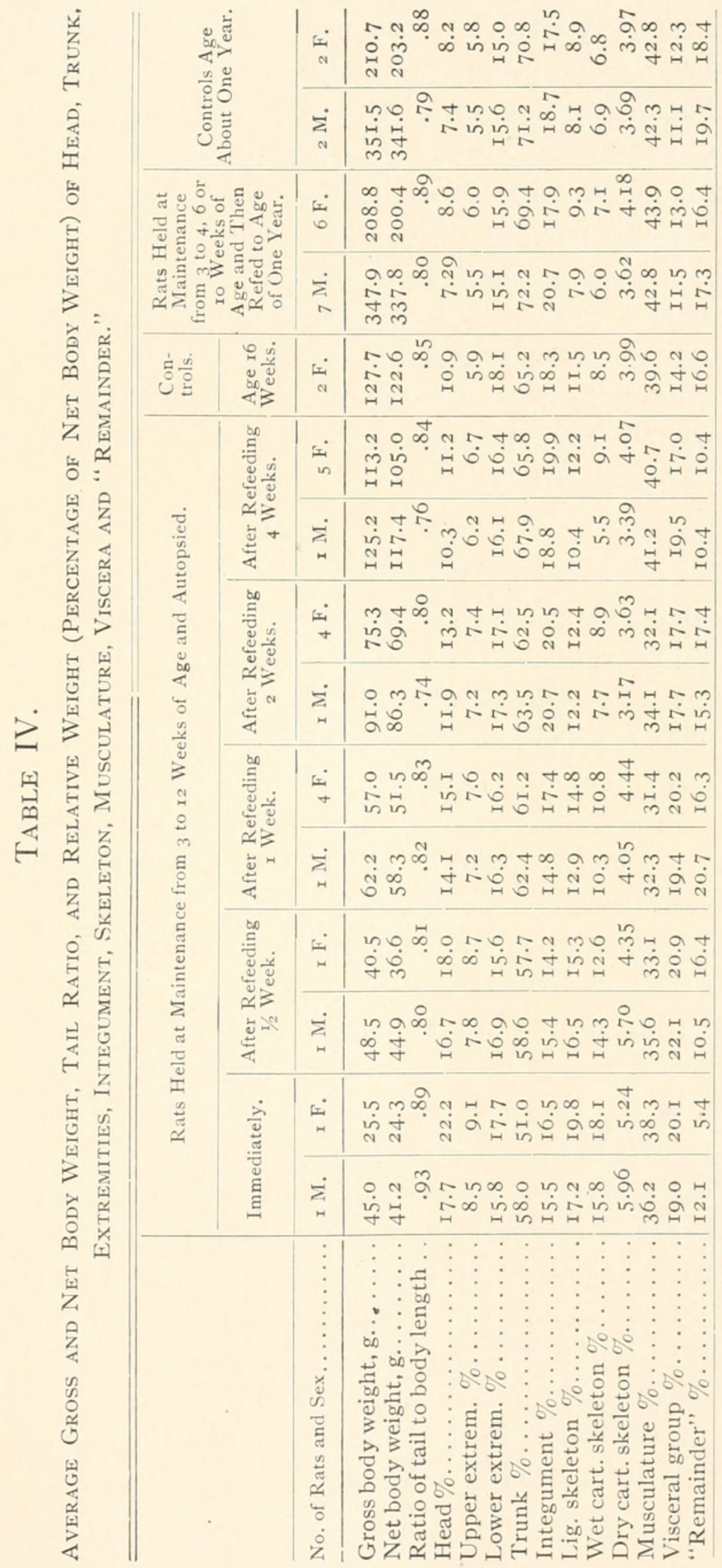


sponding body weight. In the females refed four weeks the ratio (.84) was practically identical with that in the controls (.85). For the male rat of this group the value was exceptionally low $(.76)$, as was also true of the male refed two weeks. In the adult rats the average tail-ratio was practically normal in the test males and females, as compared with the controls of the same sex.

In general, therefore, it appears that the tail and body assume the normal proportions (for corresponding body weight) in the test rats during the first week of refeeding, and remain normal at all subsequent periods. The exceptional cases are probably due to normal variability.

\section{Head (Table IV.).}

According to Jackson ('I5), the head normally forms an average of 22.5 per cent. of the body, the average net body weight being $2 \mathrm{I} .2$ grams. In the female rat killed after being kept at constant body weight (24.3 grams net) from three to twelve weeks of age, the head (Table IV.) formed 22.2 per cent. of the net body weight. In the male rat of this group the relative weight of the head (I 7.7 per cent.) was unusually low, which was due to the body weight being unusually high. It is probable that the weight of the head remained practically unchanged during maintenance, as noted by Jackson ('I5).

On refeeding (as also during normal growth) the relative weight of the head gradually decreases, reaching an average of I5.I per cent. in the females refed one week, whose net body weight averaged 5 I.5 grams. This is nearly identical with the relative weight (I5.2 per cent.) of the head observed by Jackson ('I3) for normal rats of practically the same body weight (50 grams). The relative weight of the head in the rats refed four weeks was practically the same as in the controls of the same age (Table IV.). In the adult rats the head was normal in the test animals as compared with the controls. On the whole, then, the head appears to have remained practically normal in relative weight throughout the period of refeeding. 


\section{Extremities and Trunk (Table IV.).}

The relative weight of the upper extremities 8.5 and 9.I per cent. (Table IV.) in the two rats killed at the end of nine weeks of maintenance, compares closely with the relative weight (9.3 per cent.) obtained by Jackson and Lowrey ('I2) for the normal three week rat. According to Jackson ('I5), there is apparently a slight decrease in the relative weight of the fore-limbs in the test rats from 9.3 per cent. to an average of 8.8 per cent., which, however, might be due to accidental variation.

On refeeding, the relative weight of the forelimbs gradually decreased, reaching an average of 7.4 per cent. (sexes combined) at the end of the second week, with average net body weight of 72.8 grams. Jackson and Lowrey ('I2) found the upper extremities to form on the average 6.7 per cent. of the body in rats weighing 79.2 grams net. The weight then in my rats refed two weeks, although slightly higher, is therefore nearly normal. At the end of four weeks of refeeding the upper extremities were also slightly heavier in the test rats than in the controls; but in the adult rats the relative weight was practically normal in the refed individuals, as compared with the controls.

In general, therefore, the forelimbs appear practically normal throughout the various refeeding periods, though perhaps relatively somewhat heavy at the end of two and four weeks of refeeding.

The lower extremities (Table IV.) formed I5.8 and I7.7 per cent. of the body in the two rats killed after maintenance for nine weeks. This is practically identical with the normal at three weeks of age (I5.7 per cent.) found by Jackson ('I5), who also found no distinct change in the weights of the extremities in young rats held at maintenance for considerable periods.

On refeeding, the relative weight of the lower extremities at the end of the second week averaged I 7.I per cent. of the average net body weight (72.8 grams) which is slightly higher than the value (I 4.9 per cent.) observed by Jackson and Lowrey for rats averaging 79.2 grams. At the end of four weeks of refeeding the lower extremities were relatively lighter in the test rats than in the controls, whereas in the adult the weights were practically identical in the refed and control animals. 
The relative weight of the trunk (Table IV.) averaged 54.5 per cent. in the rats killed at the end of the maintenance period, which corresponds closely with the weight (54.I per cent.) observed by Jackson for the trunk in normal rats at three weeks.

At the end of two weeks of refeeding the trunk formed an average of 62.7 per cent. (sexes combined) in the rats weighing 72.8 grams, as compared with 63.2 per cent. noted by Jackson and Lowrey in normal rats at 79.2 grams net body weight.

In the rats refed four weeks, and also in the adult test rats, the relative weight of the trunk was practically normal as compared with the controls.

The results concerning the different parts of the body therefore fail to show any decided deviation from the normal proportions throughout refeeding after various periods of maintenance.

\section{Integument (Table IV.).}

Jackson ('I5) observed that the relative weight of the integument in rats held at maintenance from three to ten weeks of age, decreased from an average of 2 I.9 per cent. to I 4.5 per cent. of the net body weight. The data for my rats show likewise a low relative weight for the integument (average of I6.0 per cent.) in rats held at maintenance for nine weeks.

At the end of the first half week, and first week of refeeding the relative weight of the integument was still unusually low in the test rats, although an increase is apparent in the females refed one week. During the second week of refeeding the integument rapidly recovered the loss suffered during inanition, forming over 20 per cent. of the body. This average is close to the normal at corresponding body weight found by Jackson and Lowrey ('I2). In the rats refed four weeks, and also in the adult test animals the integument was relatively slightly heavier than in the controls of the same age. The difference, however, is probably insignificant.

It therefore appears that on refeeding the integument rapidly recovers the loss suffered during maintenance, reaching the normal proportions within the first two weeks, and remains practically normal at all subsequent periods. 


\section{Skeleton (Table IV.).}

Three weighings were taken of the skeleton prepared as described by Jackson ('I5), who found that the skeleton increases greatly in weight during maintenance. The high relative weight of the ligamentous skeleton (I7.2-19.8 per cent.) in my two rats killed after nine weeks of maintenance as compared with Jackson's normal at three weeks ( 15.7 per cent.) is in agreement with this conclusion.

On refeeding, the relative weight of the ligamentous skeleton gradually decreases, reaching an average (in the females) of I2.4 per cent. at the end of the second week. This is slightly lower than the percentage weight (I4.0) obtained by Jackson and Lowrey for the ligamentous skeleton in normal rats of about the same body weight. It appears then that the skeleton had decreased in relative weight during the first two weeks of refeeding sufficiently to reach the normal proportions. In the rats refed four weeks, and also in the adult test rats, the relative weights of the ligamentous skeleton were practically normal as compared with the controls.

The data (Table IV.) show that a marked increase occurred also in the moist cartilaginous skeleton in the test rats during maintenance, as is evident upon comparison with the relative weight (II.4 per cent.) given by Jackson ('I5) for the normal rat at three weeks. During refeeding, the relative weight of the moist cartilaginous skeleton gradually decreased, reaching an average of I I.9 per cent. of the body in the rats refed four weeks, as compared with an average of II.5 per cent. in the controls. In the adult rats there was very little difference between the test animals and controls.

The dried cartilaginous skeleton was also relatively heavier in the maintenance rats at twelve weeks $(5.24-5.96$ per cent.) than the normal (3.43 per cent.) found by Jackson for rats at three weeks of age. On refeeding, the relative weight of the dried skeleton has decreased notably by the end of one week (Table IV.), and has probably reached the normal at two weeks. After four weeks' refeeding, and in the adults, the percentage of the dry skeleton is nearly identical in test animals and controls.

The relative amount of dry substance in the cartilaginous 
skeleton had also increased from 3I.4 per cent. (Jackson, 'I5) for the normal three weeks' rat, to an average of 34.5 per cent. in the rats killed after nine weeks of maintenance. In the rats refed four weeks the dry substance increased to 45.9 per cent. of the moist cartilaginous skeleton, which is fairly close to that found in the control (46.6 per cent.).

It therefore appears that the ligamentous and cartilaginous skeletons reach the normal proportions during the first two weeks of refeeding. This is probably true also for the dry skeleton, although controls are lacking before the fourth week.

\section{Musculature (Table IV.).}

In the two rats killed at the end of nine weeks of maintenance the relative weight of the musculature $(36.2-38.3$ per cent.) is considerably higher than the norm (3I.2 per cent.) obtained by Jackson ('15) for the three weeks' rat. This may be due partly to an increase in the musculature during maintenance (a slight increase being found by Jackson). The body weight is above normal in these two rats, however, in which case the musculature would normally be relatively heavier. For the normal rat at 42.4 grams, Jackson found the musculature forming 35.3 per cent., although at 64.4 grams body weight Jackson and Lowrey ('I2) found the musculature forming 32.7 per cent.

In my test rats refed one half week (average net weight 40.7 grams) the musculature averaged 34.3 per cent., whereas in the female rats refed two weeks (average net weight 69.4 grams) the musculature formed only 32. I per cent. of the body. There is evidently considerable individual variation, and it is difficult to make the dissection of the musculature in a uniform manner. In the rats refed four weeks, and also in the adult test animals the percentage weight of the musculature was nearly identical with that of the controls.

From the foregoing it may be concluded that the musculature (which possibly was slightly heavier than the normal for body weight at the end of maintenance), assumed practically the normal proportions during the first week of refeeding and remained normal at all subsequent periods. 


\section{Viscera and "Remainder" (Table IV.).}

The relative weight of the visceral group (including the abdominal and thoracic viscera, spinal cord, brain and eyeballs) in the rats killed at the end of the fasting period corresponds closely with the weight (20.5 per cent.) found by Jackson ('I5) for the normal rat of three weeks. Concerning the visceral group, Jackson noted during maintenance a distinct tendency to increase in weight, which was more marked at six and eight than at ten weeks. The fact that my rats fail to show an increase in the relative weight of the visceral group probably is due to their longer period of stunting, during which the liver especially tends to decrease in weight.

According to Jackson and Lowrey, the relative weight of the visceral group is $2 \mathrm{I} .3$ and 20.4 per cent. of the body at three and six weeks of age, the net body weight averaging 24.8 and 64.4 grams respectively. In my rats refed one week and less, the relative weight of the viscera (Table IV.) in all cases formed about 20 per cent. of the body, thus being approximately normal. At the end of two weeks of refeeding however the visceral group appears exceptionally light, the relative weight being 17.7 per cent. as compared with 20.4 per cent. given above for the normal rat of about the same body weight ( 64.4 grams). After four weeks of refeeding the viscera collectively were relatively heavier in the test rats than in the controls, whereas in the adult rats the weights are nearly identical in the test animals and controls.

In general it therefore appears that the relative weight of the visceral group was about normal during the refeeding. A considerable variation in the weight of the visceral group is not unusual.

The weight of the "remainder" (Table IV.), which includes some small unweighed organs, fat, and body-fluids, was obtained by deducting the weight of the integument, skeleton, musculature, and viscera from the net body weight. The data show considerable variation but it is doubtful whether there is any material change from the normal during refeeding in the test rats. 


\section{Brain (Table V.).}

The brain shows but little deviation from Donaldson's ('I5) Wistar norm for rats of same body length in either the rats killed at the end of maintenance or in those refed for various periods. Such slight fluctuations from the norm as are shown in the table are probably within the range of normal variation. Jackson ('I5) noted that there was practically no change in the brain weight of young albino rats held at constant body weight for considerable periods.

It may therefore be concluded that the brain weight is normal in the young rats at the end of the maintenance period, and remains normal throughout the period of refeeding.

\section{Io. Spinal Cord (Table V.).}

The weight of the spinal cord in the two rats killed at the end of the maintenance period exceeded Donaldson's norm, 34.3 and I9.9 per cent. This confirms Jackson's ('I5) observation that the spinal cord shows a marked growth in young rats held at constant body weight.

On refeeding, this excess weight (as compared with normal for corresponding body length) rapidly disappeared, so that by the end of the first week the weight of the spinal cord exceeds Donaldson's norm only 7.3 and 3.2 per cent. in the I male and 4 females respectively. Thus the spinal cord had nearly regained the normal proportion.

At the end of two and four weeks of refeeding the weight of the spinal cord was slightly below the Wistar norm, as was also true of the controls at sixteen weeks of age. This condition therefore appears to be normal for my series of rats and not an experimental modification.

In the test rats (refed after maintenance for various periods) killed at the age of one year the weight of the spinal cord was normal as compared with the controls, although in each case the average weight was 8 to Io per cent. heavier than Donaldson's norm.

In general therefore the results indicate that the spinal cord, which was relatively heavy at the end of the maintenance period, returned to the normal proportion during the first two weeks of refeeding, and remained normal after that time. 


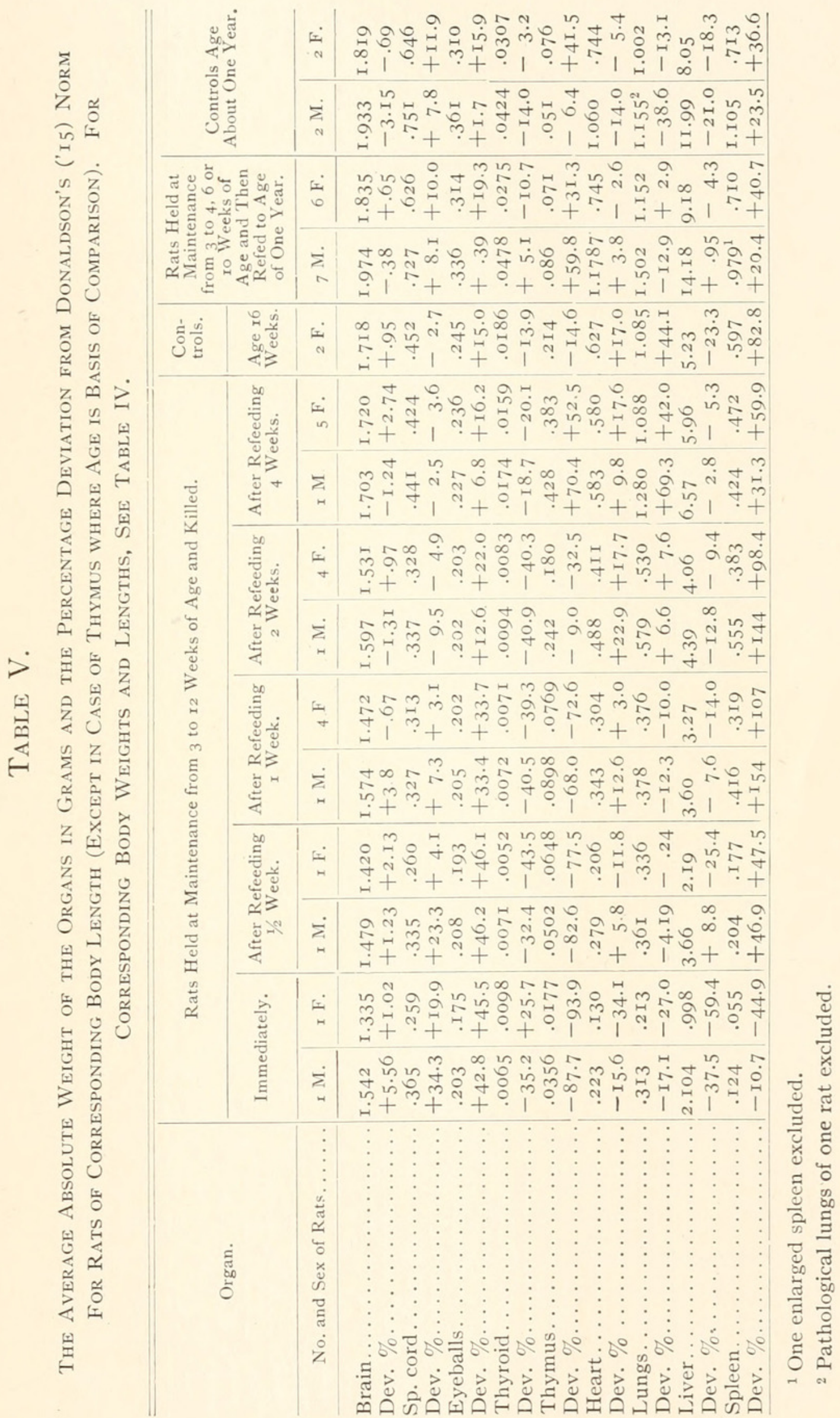




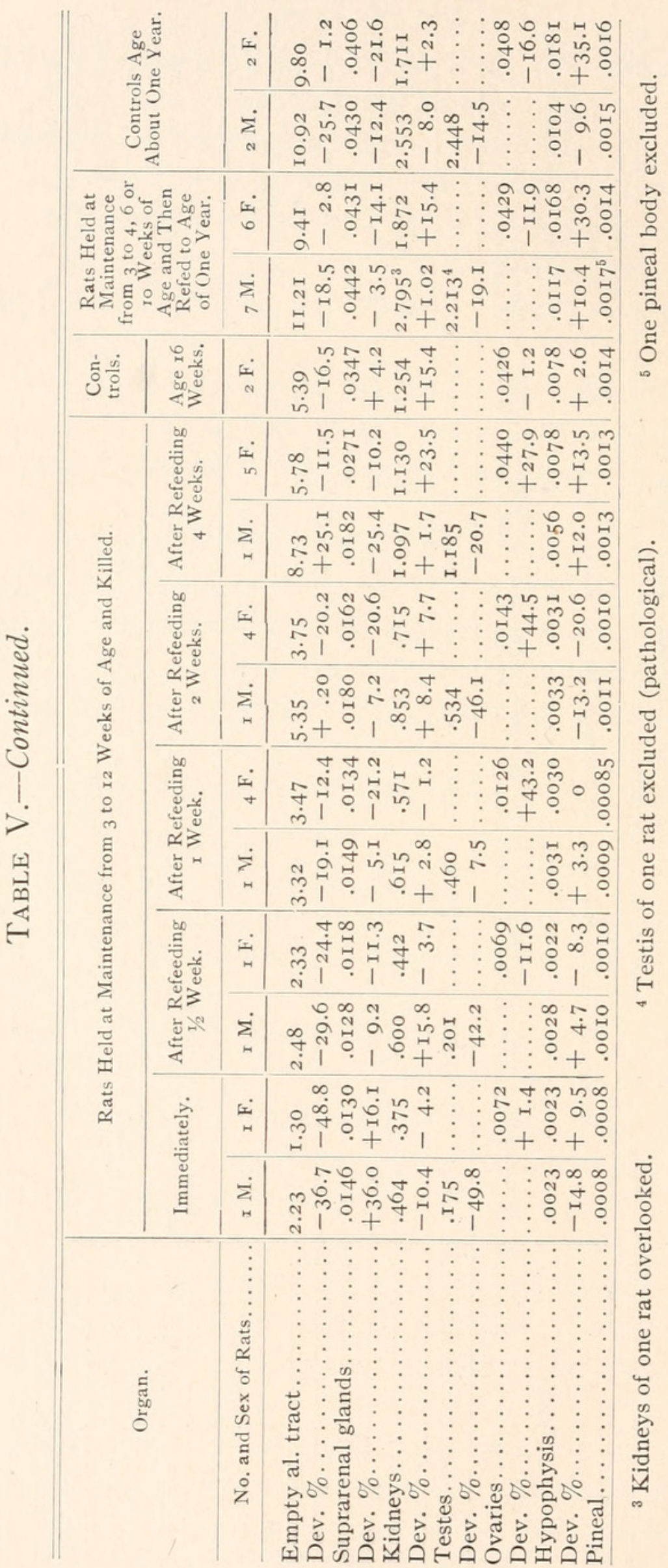




\section{I. Eyeballs (Table V.).}

As compared with Donaldson's ('I5) norm, the eyeballs were excessively heavy (plus 42.8 and 45.5 per cent.) in the two rats killed at the end of nine weeks of maintenance. The persistent growth of the eyeballs in young rats held at constant body weight was discovered by Jackson ('I5). In the rats refed one half, one, and two weeks the eyeballs are still relatively heavy as compared with Donaldson's norm, although the difference has decreased somewhat during these periods. Even in the rats refed four weeks the eyeballs are still somewhat above Donaldson's norm, but are practically normal as compared with my controls.

Likewise in the adult refed rats, as compared with the controls, the eyeballs appear to be normal in weight, although in the females they somewhat exceed the Wistar norm in weight.

The evidence therefore indicates that the eyeballs, which were relatively heavy at the end of the maintenance period, returned to the normal proportion by the end of the fourth week of refeeding, and were normal in the adult test rats.

\section{I2. Thyroid (Table V.).}

At the end of the maintenance period the weight of the thyroid in the male rat was 35.2 per cent. below the Wistar norm, while in the female it was 25.7 per cent. above. Jackson ('I5) noted that the thyroid suffered a marked loss during maintenance. The exceptionally large weight for the female above noted may be due to experimental error or normal variation. On refeeding, the thyroid remains below Donaldson's Wistar norm, although by the fourth week it is only I 8.7 to 20 .I per cent. below. In the controls for this group the weight of the thyroid is also below Donaldson's norm by I3.9 per cent., which deducted from the minus 20.I per cent. for the test females leaves 6.2 per cent. loss apparently produced by the fasting experiment. In view of the known variability of the thyroid, this difference is too small to be considered significant. We may therefore conclude that the thyroid gland has probably recovered its normal weight during the four weeks of refeeding. In the adult rats the fluctuations in the weight of the thyroid gland are likewise well within the 
limits of normal variability, and show no indications of any persistent effects of the earlier maintenance period.

\section{I3. Thymus (Table V).}

The weight of the thymus at the end of the maintenance period was from 87.7 to 93.9 per cent. below Donaldson's norm. This agrees closely with Jackson's ('I5) observation of 90 per cent. loss in the weight of the thymus due to "hunger involution" during maintenance in young rats from the age of 3 to Io weeks. At the end of two weeks of refeeding, the thymus was still somewhat below Donaldson's norm (9.0 to 32.5 per cent.); but at the end of the fourth week it exceeded the norm 70.4 and 52.5 per cent. in the male and female test rats respectively, while the controls averaged 14.6 per cent. below. It is therefore evident that the thymus returned to the normal proportion between the second and fourth weeks of refeeding. The weight of the thymus in the test rats refed four weeks was remarkably high, indicating a marked over-compensation of the loss during "hunger involution."

In the adult rats the thymus was relatively heavier in the female controls than in the female test rats, whereas the converse was true of the males. This inconsistency, together with the known variability in the normal weight of the thymus (average coefficient of variation is 34 , according to Jackson, 'I3) makes it doubtful whether the result is due to the experimental conditions or is due merely to normal variation. Further observations will be necessary to determine this question.

The results in general therefore indicate that in the stunted rats, the thymus returns to the normal proportion shortly after the second week of refeeding, and greatly exceeds the normal at the end of the fourth week. The data for rats refed to the adult stage indicate the possibility of a permanent over-compensation in the growth of the thymus upon refeeding after a period of maintenance.

Jonson ('o9) subjected a rabbit (age 6 weeks) to inanition for 3I days, during which time the body weight increased from 553 to 655 grams. The animal was then refed for three weeks, at the end of which time the weight of the thymus was found 
normal as compared with the weight in a control killed at the end of the fasting period.

Salkind ('I5) observed that a minimum of at least one week of refeeding was necessary to restore the normal lymphoid structure of the thymus in rats suffering severe starvation for two days.

\section{I4. Heart (Table V).}

The heart at the end of the maintenance period was I5.6 and 34.I per cent. below Donaldson's norm of weight. Jackson ('I5), however, noted practically no change in the weight of the heart during maintenance. The discrepancy in my rats may possibly be due either to normal variation or to experimental error.

At the end of the various refeeding periods the heart (with one exception) was heavier than Donaldson's norm, the excess varying from 3.0 to 22.9 per cent. At the end of four weeks of refeeding, the weight of the heart in the test females exceeded the Wistar norm I 7.6 per cent. while the controls exceeded it by I 7.0 per cent. The heart therefore appears practically normal in weight at sixteen weeks in the refed rats as compared with the controls. This was also true for the adult animals.

In general, therefore, it may be concluded that the heart was probably nearly normal in the test rats throughout refeeding, although it appears relatively heavy (in comparison with Donaldson's norm) during the earlier weeks of refeeding.

\section{I5. Lungs (Table V.).}

The weight of the lungs was I7.I and 27.0 per cent. below the Wistar norm at the end of nine weeks of maintenance, indicating a decrease in size during that period. Jackson ('I5) found a loss of about I5 per cent. during seven weeks of maintenance. The lungs were also somewhat below the norm during the first week of refeeding, but somewhat above thereafter. The excess was especially marked in the rats refed four weeks (42.0 to 69.3 per cent.), but the controls also showed an excess weight of 44. I per cent. This excess might be due to an over-compensation of growth, or merely to variability from other causes (possibly pathological, due to slight pulmonary infection). In the adult rats the lungs were smaller than the norm except in the case of 
the test females, which were slightly larger. The differences are probably due to individual variation.

The results therefore indicate that the lungs, which lose weight during maintenance, completely recovered within two weeks of refeeding. There is possibly an over-compensatory growth before the end of four weeks, but no indication of such in the animals refed to the adult stage.

\section{I6. Liver (Table V.).}

The weight of the liver in the two rats killed at the end of nine weeks of maintenance was 37.5 and 59.4 per cent. below Donaldson's norm for the male and female respectively. (However, Jackson ('I3) found the normal liver weight, especially in young rats, considerably below the curve derived from Hatai's formula, upon which Donaldson's norm is based.) Jackson ('I5) found the liver to increase in weight in rats held at maintenance from three to six and ten weeks of age, but it decreased in those held for longer periods (from six to thirty-two weeks of age). The low weight of the liver for my rats at the end of the maintenance period was probably due in part to the length of their maintenance period.

During the first four weeks of refeeding the weight of the liver was below Donaldson's norm, except in the male refed one half week. In most instances, however, especially after the first week, the deviations are within the limits of normal variation. In the controls at sixteen weeks, however, the weight of the liver was 23.3 per cent. below the norm, while in the test females of the same age it was but 5.3 per cent. below. Thus when compared with Donaldson's norm, the liver is about normal in the test rats refed four weeks, but when compared with the controls it is relatively heavy.

In the adult test rats the weight of the liver was very close to Donaldson's norm, but very low ( $-\mathrm{I} 8.3$ to $-2 \mathrm{I} .0$ per cent.) in the controls.

Therefore in comparison with the Wistar norm the liver appears practically normal after the first week of refeeding. As compared with the controls, however, there is some indication of hypertrophy in the liver of the rats refed four weeks, and also in 
the adult test animals. It is more probable that this apparent increase is due merely to normal variability, which is quite large in the liver.

\section{I7. Spleen (Table V.).}

Jackson ('I5) noted a considerable decrease in the weight of the spleen in rats held at maintenance from three to eight and ten weeks of age. My data (Table V.) likewise indicate that the spleen is low in weight at the end of nine weeks of underfeeding (minus I0.7 and 44.9 per cent.) when compared with Donaldson's norm.

On refeeding, at all periods the weight of the spleen was much higher than Donaldson's norm, the excess appearing greater at one and two weeks of refeeding, than at later periods. In the controls the spleen likewise exceeded the Wistar norm, 82.8 per cent. at sixteen weeks, and 23.5 and 36.6 per cent. in the adult control males and females respectively. As compared with the controls the spleen was practically normal in the adult test rats.

In this connection it may be noted that, as was pointed out by Jackson ('I3), Hatai's formula for the growth of the spleen (upon which Donaldson's norm is based) gives a curve which in general is too low (excepting the earlier stages), because he excluded all "enlarged" spleens from the series, without apparent justification. In most cases, however, the spleens of my refed rats appear considerably heavier even than Jackson's curve. The fact that the weight of the spleen is normally exceedingly variable, as shown by Jackson ('I3) must also be kept in mind.

In general therefore the results indicate that upon refeeding the spleen rapidly (within $1 / 2$ week) recovered the loss suffered during fasting. There is apparently an excessive (over-com. pensatory) growth of the spleen during the first two weeks of refeeding. At the end of the fourth week, however, and in the adult rats the spleen in the test animals is not above that of the controls.

\section{I8. Stomach and Intestines (Table V.).}

The weight of the empty alimentary tract at the end of maintenance was much below the Wistar norm (minus 36.7 to 48.8 per cent.). My data, however, are somewhat above the weights 
observed by Jackson ('I5) for the empty tract (in controls at body weight of $25 . \mathrm{I}$ and $42.4 \mathrm{~g}$.). This would indicate an increase in the weight of the tract during maintenance, in agreement with Jackson ('I5).

On refeeding, with the exception of the male refed four weeks, the weight of the empty alimentary tract increased in relative size, but remained below the Wistar norm in most cases. It was higher in the refed rats than in the controls at the age of I 6 weeks (end of fourth week of refeeding). In the adult rats the weight of the empty stomach and intestines was practically normal in the test rats as compared with the controls, although below the Wistar norm, especially in the males.

The relative weight of the stomach and intestines including contents (I2.6 per cent.) in the two rats killed at the end of nine weeks of maintenance averaged close to that observed by Jackson ('I5) in rats held at maintenance for seven weeks. This is slightly higher than the normal relative weight (I0.4 per cent.) at three weeks, the beginning of the maintenance period. In the female rats refed one week the tract and contents formed I6.2 per cent. of the body weight, as compared with I5.4 per cent. noted by Jackson ('13) for normal rats of corresponding body weight (50.4 grams net). At the end of four weeks of refeeding, the relative weight of the stomach and intestines (I 3.5 per cent.) for the test rats was considerably above that ( 9.0 per cent.) in the controls. In the adult rats, the relative weight of the tract and contents for the controls and test rats respectively was 6.0 and 6.3 per cent. in the males, and 8.5 and 8.8 per cent. in the females.

In general therefore it may be concluded that the stomach and intestines including contents were heavier than normal for corresponding body weight at the end of the fasting period, but were practically normal at the end of two weeks of refeeding, and thereafter. Considerable allowance must be made for individual variations, which probably account for the apparent increase at the fourth week of refeeding.

\section{I9. Suprarenal Glands (Table V.).}

The weight of the suprarenal glands in the male and female rats killed after maintenance for nine weeks exceeded Donaldson's 
norm plus 36.0 and I6.I per cent., respectively. The relative weights of the glands (.054 per cent. for the female and .035 per cent. for the male) shows that sexual differentiacion in weight had appeared. An increase with sexual differentiation in the weight of the suprarenal glands in young rats held at maintenance was likewise observed by Jackson ('I5).

Following refeeding, the weight of the suprarenals was constantly below the Wistar norm to a variable extent for the first four weeks. In the controls at sixteen weeks of age, the suprarenals were slightly ( 4.2 per cent.) above the norm. This would indicate that the excess weight accumulated by the suprarenal glands while the body weight remained constant did not persist; but on the contrary the glands appear to lag behind their normal proportions in the growth of the body upon refeeding. It is of course barely possible that this deficiency in the weight of the suprarenals in the refed rats may be due to chance variations.

In the adult rats, the suprarenals were also below Donaldson's norm, but as compared with the controls the glands were slightly heavier in the test animals. The differences however are small, and probably not significant.

It may therefore be concluded that the suprarenals, in which growth is persistent during maintenance, lag behind upon refeeding and appear even to drop below the norm. In those refed to the adult stage, however, there is no marked difference between test animals and controls.

\section{Kidneys (Table V.).}

The kidneys appear to be slightly below normal weight for corresponding body length at the end of nine weeks of underfeeding. The differences, however, are small and probably not significant. Jackson ('I5) observed that in rats held at constant body weigh t there was a slight tendency to increase in the weight of the kidneys, in the earlier weeks, but little or no apparent difference later.

During the first four weeks of refeeding, in the majority of cases the kidneys were slightly heavier than Donaldson's norm. At sixteen weeks, the kidneys were 23.5 per cent. above the norm in the female refed rats, and 15.4 per cent. in the controls. 
In the adult rats the kidneys in both test animals and controls were close to Donaldson's norm. It is evident therefore that the kidneys were practically normal in weight, both at the end of the fasting period, and throughout the period of refeeding.

\section{I. Testes and Epididymi (Table V.).}

On account of the small number of observations, conclusions concerning the testes and epididy mi are rather unsatisfactory during the early periods of refeeding. As compared with Donaldson's norm, the testes appear to be constantly below normal weight, especially at the end of the maintenance period (contrary to the observations of Jackson). In the adult rats, however, these glands are practically normal as compared with the controls.

The epididymi are not included with the testes in Table V. Their relative weight (.092 per cent. of net body weight) in the male rat killed at the end of nine weeks of maintenance, was close to the average given by Jackson ('I5) for the normal at three weeks (.084 per cent.) and in rats held at maintenance for seven weeks (.080 per cent.). At the end of four weeks of refeeding the relative weight of the epididymi (.I2 per cent.) the net body weight being II 7.4 grams, appears to be unusually low. In the adult rats the relative weight of the epididymi averaged .27 per cent. in the con irols and.2 I per cent. in the test animals.

On account of the great normal variability in the weight of both testis and epididymis, and the small number of observations, no conclusions can be drawn with any degree of certainty. However, the evidence indicates that the testes and epididymi were somewhat below normal weight during the early refeeding periods, but practically normal in the adult animals.

\section{Ovaries (Table V.)}

The ovaries were practically normal as compared with Donaldson's norm in the female rat at the end of the underfeeding period. Jackson ('I5) noted an apparent decrease in the weight of the ovary during maintenance.

On refeeding, the ovaries were below Donaldson's norm (minus I I. 6 per cent.) at the end of the first half-week, but exceeded it 
(plus 43.2, 44.5 and 27.9 per cent.) at one, two, and four weeks of refeeding. After four weeks of refeeding (I6 weeks of age) the ovaries were practically normal in the controls. In the adult rats the ovaries in both test animals and controls were somewhat below Donaldson's norm.

It therefore appears that the ovaries on refeeding became heavier than the norm during the earlier periods, reaching a maximum excess weight during the second week, and decreasing to the norm, or below, before the adult stage was reached. However, the large amount of variability in the normal weight of the ovary (due to changes during the sexual cycles) makes any definite conclusions from the available data very difficult or impossible.

\section{Hypophysis (Table V.).}

The weight of the hypophysis at the end of the fasting period was I 4.8 per cent. below Donaldson's norm in the male and 9.5 per cent. above it in the female. Jackson ('I5) noted a distinct tendency for the hypophysis to increase in weight in young rats held at maintenance.

On refeeding, the hypophysis shows no constant variation from Donaldson's norm. At the end of the fourth week in the test females it was 13.5 per cent. above the norm, whereas the controls were 2.6 per cent. above. The difference is probably due to normal variation and of no special significance.

In the adult rats the hypophysis weight in both controls and test animals shows considerable variation from the Wistar norm, being especially high in the females.

The evidence therefore indicates that the hypophysis was practically normal in weight at all times during the process of refeeding.

\section{Pineal Body (Table V.).}

On account of lack of data for comparison, no conclusions can be drawn concerning the pineal body in the rats killed at the end of the underfeeding period, and in those refed one half, one, and two weeks. The observations are recorded in Table V.

In the test rats refed four weeks the gland was apparently normal, the relative weight being .oor 23 and .ooII per cent. 
of the body weight in the male and females respectively, as compared with .oor 6 per cent. in the controls of the same age.

In the adult rats, the relative weight of the pineal body was .00042 per cent. in the control males and .00050 per cent. in the test males. For the females, the relative weight was .00066 per cent. in the controls and .00067 per cent. in the test animals.

The differences in relative weight between males and females are probably due to the difference in body weight. There is no indication of a sexual difference in animals of the same body weight (such as has been found in the suprarenals, hypophysis and parathyroids), which is in accord with the conclusion of E. R. Hoskins (at present unpublished) based upon data collected in this laboratory.

It appears therefore that the pineal body was of normal weight in the rats refed four weeks and one year.

\section{Conclusion.}

The present experiments have shown that the marked tendency of the body as a whole in young rats to recover its weight after a period of maintenance is likewise characteristic of the various organs and parts. The abnormal proportions produced by underfeeding rapidly disappear upon generous refeeding, so that practically the normal relations are restored in most cases within four weeks. This readjustment evidently involves a modification of the growth curves of many of the various organs and parts of the body during the early refeeding periods. Thus those organs and parts which lost weight during maintenance grow more rapidly than the body as a whole, whereas those which gained weight during the maintenance period show a tendency to lag behind until the normal balance is restored.

\section{SumMary.}

The more important results of the present investigation may be summarized as follows:

The average daily gain in weight of the young rats refed after being held at constant body weight for short repeated periods was somewhat higher than that of the controls. This enabled the test rats to make up lost time and to overtake the controls, but not to exceed them in body weight. 
The average daily loss in weight did not increase in the rats on successive periods of severe fasting, involving a loss of 25 per cent. of the initial weight.

The increment of body weight upon refeeding the test rats after each severe fast amounted to only about i 6 per cent. of the ingested food (exclusive of water).

The amount of food required daily for maintenance decreased during the first fifty days of the experiment, but after that time apparently no further diminution occurred.

The growth in body weight of the rats refed after maintenance for various periods averaged for some time considerably higher than the normal for the (younger) controls of corresponding initial weight. Thus the stunted rats were able to overtake the full-fed controls in body weight before the end of the normal growth period. No effect of the stunting upon the ultimate body weight was noted.

As to the body proportions, the relative weights of the head, trunk and extremities remain practically normal during the various periods of refeeding.

Of the systems, the musculature and "remainder" continue practically normal for corresponding body weight during the various periods of refeeding. The integument rapidly increases, and the skeleton decreases, in relative weight, so that both reach approximately the normal proportions within the first two weeks of refeeding after maintenance from three to twelve weeks of age.

The viscera which are known to lose weight during maintenance-thymus, spleen, thyroid, lungs and ovaries-likewise apparently regain their normal relative weight within two weeks after refeeding. The thymus, and possibly the lungs, spleen, and ovaries, are apparently even above normal (over-compensatory growth) at four weeks of refeeding, but all are found practically normal in the rats refed to the adult stage.

The viscera whose weight remains nearly constant during maintenance-brain, heart, kidneys, liver, and epididymi-in general present approximately normal proportions during the process of refeeding; although the heart appears slightly above normal and the epididymi somewhat below.

The viscera whose weight increases during maintenance- 
eyeballs, spinal cord, alimentary canal, hypophysis, testes and suprarenals-have in general decreased in (relative) weight so as to approach the normal within the first four weeks of refeeding. The testes and the suprarenals may even become subnormal in weight during the first four weeks of refeeding, but all are practically normal in the rats refed to the adult condition.

The pineal body was approximately normal in weight in the test rats refed four weeks, and in the adult test animals. There was no evidence of a sexual difference in the weight of the pineal body in rats of corresponding body weight.

\section{LITERATURE CITED.}

Aron, $\mathrm{H}$.

'II Nutrition and Growth. Philippine Journal of Science, Vol. 6, pp. I-5I.

'I4 Untersuchungen über die Beeinflussung des Wachstums durch die Ernäh. rung. Berliner klin. Wochenschr., J. 51, S. 972-977.

Boas, F.

'I2 The Growth of Children. Science, N. S., vol. 36, pp. 8I5-8I8.

Brüning, $\mathrm{H}$.

'I4 Experimentelle Studien über die Entwicklung neugeborener Tiere bei längerdauernder Trennung von der säugenden Mutter und nachheriger verschiedenartiger künstlicher Ernährung. Jahrb. f. Kinderheilk., Bd. 8o, S. $65-85$.

Child, C. M.

'I5 Senescence and Rejuvenescence. The University of Chicago Press.

Donaldson, H. H.

'I5 The Rat. Reference Tables and Data for the Albino Rat and the Norway Rat. Memoirs of The Wistar Institute of Anatomy and Biology, No. 6.

Ferry, Edna L.

'r3 The Rate of Growth of the Albino Rat. Anat. Record, Vol. 7, No. I 2.

Hatai, S.

'o7 Effect of Partial Starvation Followed by a Return to Normal Diet on the Growth of the Body and Central Nervous System of Albino Rats. Amer. Jour. Physiol., Vol. I7.

Jackson, C. M.

'I2 On the Recognition of Sex through External Characters in the Young Rat. Biol. Bull., Vol. 23.

'I3 Postnatal Growth and Variability of the Body and of the Various Organs in the Albino Rat. Amer. Jour. Anat., Vol. I5.

'I5 Changes in the Relative Weights of the Various Parts, Systems and Organs of Young Albino Rats Held at Constant Body Weight by Underfeeding for Various Periods. Jour. Exper. Zool., Vol. I9.

Jackson, C. M., and Lowrey, L. G.

'I2 On the Relative Growth of the Component Parts (Head, Trunk, and Extremities) and Systems (Skin, Skeleton, Musculature and Viscera) of the Albino Rat. Anat. Record, Vol. 6. 
Jonson, A.

'o9 Studien über die Thymusinvolution. Die akzidentelle Involution bei Hunger. Arch. f. mikr. Anat., Bd. 73, S. 390-443.

\section{Kahan, J.}

'85 Der Einfluss des Hungerns auf das Körpergewicht bei der Auffütterung von Thieren mit einer beschränkten Nahrungsmenge nach einem überstandenen Hunger. Russ. Medicin, No. I7-19. (Cited by Mühlmann, Centralbl. f . allg. Pathol., Bd. I0, I899.)

\section{King, Helen D.}

'I5 Growth and Variability in the Body Weight of the Albino Rat. Anat. Record, Vol. 9, No. io.

\section{Minot, S.}

'o8 The Problem of Age, Growth and Death. New York.

\section{Morgulis, S.}

'II Studies of Inanition in Its Bearing upon Growth. Arch. f. Entwicklungsmech. Bd. 32 .

Noè, Joseph

'oo La réparation compensatrice après le jeune. Comptes Rend. Soc. Biol., Paris. T. 52 .

Osborne, T. B., and Mendel, L. B.

'I5 The Resumption of Growth after Long-continued Failure to Grow. Jour. of Biol. Chem., Vol. 23,

'ı6 Acceleration of Growth after Retardation. Amer. Joụr. Phys., Vol. 40, No. I.

\section{Salkind, J.}

'I5 Contributions histologiques à la biologie comparée du thymus. Arch. de Zool. Exper., T. 55, Fasc. 5.

\section{Schapiro, A.}

'05 On the Influence of Chloroform on the Growth of Young Animals. Proc. Physiol. Soc., Journ. Physiol., Vol. 33, p. 3I.

\section{Schloss, E.}

'I I Die Pathologie des Wachstums im Säuglingsalter. Berlin.

\section{Seland.}

'88 Ueber den Einfluss der Nahrungsentziehung auf die nachfolgende Ernährung. Russ. Medicin. (Cited by Mühlmann, Centralbl. f. allg. Pathol., Bd. I0, I899).

\section{Springer, Ada.}

'o9 A Study of Growth in the Salamander, Diemyctylus viridescens. Jour. of Exper. Zool., Vol. 6.

\section{Stewart, C. A.}

'I6 Growth of the Body and of the Various Organs of Young Albino Rats upon Refeeding after Inanition for Various Periods. Anat. Record, Vol. Io, No. 3 . 


\section{$2 \mathrm{BHL}$ Biodiversity Heritage Library}

Stewart, Chester A. 1916. "GROWTH OF THE BODY AND OF THE VARIOUS ORGANS OF YOUNG ALBINO RATS AFTER INANITION FOR VARIOUS PERIODS." The Biological bulletin 31, 16-51. https://doi.org/10.2307/1536231.

View This Item Online: https://www.biodiversitylibrary.org/item/15845

DOI: https://doi.org/10.2307/1536231

Permalink: https://www.biodiversitylibrary.org/partpdf/20760

\section{Holding Institution}

MBLWHOI Library

\section{Sponsored by}

MBLWHOI Library

\section{Copyright \& Reuse}

Copyright Status: NOT_IN_COPYRIGHT

This document was created from content at the Biodiversity Heritage Library, the world's largest open access digital library for biodiversity literature and archives. Visit BHL at https://www.biodiversitylibrary.org. 